\title{
Value-added wood composites made from waste polystyrene as a binder: A review
}

\author{
Dafni Foti ${ }^{1}$, Elena Voulgaridou${ }^{1}$, Sotirios Karastergiou ${ }^{2}$ and Antonios N. Papadopoulos ${ }^{* 1}$ \\ ${ }^{1}$ Department of Forestry and Natural Environment, International Hellenic University, GR-66100, Drama, \\ Greece; antpap@for.ihu.gr, dfoti@for.auth.gr, v_elena7@hotmail.com \\ ${ }^{2}$ Department of Forestry, Wood Sciences and Design, University of Thessaly, GR-43100, Karditsa, Greece; \\ karaso@uth.gr \\ *Correspondence: antpap@for.ihu.gr (A.N.P)
}

\begin{abstract}
Wood composites is a growing field of products that are increasingly present for a variety of applications, with an undiminished upward trend now for very many decades. It must be clearly pointed out that one cannot speak about wood composites without speaking in depth of the polymer binders used to hold them together. Synthetic adhesives do still dominate this market and are mostly based on formaldehyde. There are also several biobased adhesives based on renewable natural materials that are at the forefront of new developments. Some of these are already industrial, sometime for many years, such as tannin adhesives and some soy adhesives, while others are on the way of industrialization, and many others are, as yet, at the experimental stage. Nowadays, the products manufactured from recycled materials are especially paid attention in the view-point of environmental problems. Polystyrene is a synthetic, aromatic, thermoplastic polymer made from the monomer styrene. Waste polystyrene poses serious environmental risks especially in developing countries where disposal facilities are lacking and its management is a serious problem because it is easy to recycle. Due to the lack of effective strategies of polystyrene waste recycling, most of it is discarded in recycling plants, landfills or incinerated. In this context, an option to successfully utilize waste polystyrene and at the same time to avoid the environmental problems that formaldehyde adhesives cause, is its application as a binder in order to produce value-added wood composites. This paper reviews the research milestones in this area and discusses the potential of using waste polystyrene as a binder in producing value-added wood composites.
\end{abstract}

Keywords: wood; wood composites; binders; adhesives; polystyrene

\section{Introduction}

Wood composites are manufactured from a variety of materials. They usually contain the same woods that are used in lumber, but they are combined to make them stronger and more durable. Wood has long been used as a construction material and revered for its strength and natural aesthetics. The main advantage of wood composites is that they can be designed for specific performance requirements or specific qualities, since they are man-made. Therefore, they can be used in a very wide array of applications, from small-home to industrial-scale projects. This, in turn, enables many more options in design without sacrificing structural requirements. At the same time, their ability to be tailored to a number of uses makes them a very viable option for reducing the use of solid wood. It must be clearly pointed out that one cannot speak about wood composites without speaking in depth of the polymer binders and adhesives used to hold them together. The history of 
The 1st International Electronic Conference on "Green" Polymer Materials 2020, 5-25 November 2020

wood composites themselves is inextricably intertwined with the history and the development of the polymer binders that hold them together and their manufacture. In fact, not only has there been continuous development of new or improved binders that has allowed the development of wood composites but it is the continual renewal, new discovery, and upgrading of such binders that has allowed and allows progress in wood composites [1].

While the wood composite industry, mainly for reason of supply, is still dominated by traditional oil-derived adhesives, both in these fields as well as in the strongly upcoming field of biobased adhesives, there has been almost incredible progress as well as developments dictated by the intellectual ferment induced by a number of outside constraints. These are the stricter government regulations to reduce and even eliminate formaldehyde and other materials that are to some extent toxic, consumer awareness and the consequent drive of industry to favor more environment-friendly materials and, finally, the drive of industry to decrease or even eliminate their dependence on petrochemicals, due to the real or imagined future decrease of oil reserves with its consequent increase in the price of raw materials for purely traditionally manufactured wood binders [2].

Nowadays, the products manufactured from recycled materials are especially paid attention in the view-point of environmental problems. Polystyrene is a synthetic, aromatic, thermoplastic polymer made from the monomer styrene. Waste polystyrene poses serious environmental risks especially in developing countries where disposal facilities are lacking and its management is a serious problem because it is easy to recycle. In this context, an option to successfully utilize waste polystyrene and at the same time to avoid the environmental problems that formaldehyde adhesives cause, is its application as a binder in order to produce value-added wood composites. This paper briefly presents the binders used in wood composites industry and discusses the potential of using waste polystyrene as a binder in producing value-added wood composites.

\section{Wood Composite Adhesives}

An excellent and updated review on wood composites and the polymer binders used for their manufacture is recently published [3]. The review focused on the most important aspects look out for in manufacturing excellent wood composites and on binders that currently dominate in industry, as depicted in Figure 1. The review concluded that while the wood composite industry, mainly for reason of supply, is still dominated by traditional oil-derived adhesives, both in these fields as well as in the strongly upcoming field of biobased adhesives, there has been almost incredible progress as well as developments dictated by the intellectual ferment induced by a number of outside constraints. These are the stricter government regulations to reduce and even eliminate formaldehyde and other materials that are to some extent toxic, consumer awareness and the consequent drive of industry to favor more environment-friendly materials and, finally, the drive of industry to decrease or even eliminate their dependence on petrochemicals, due to the real or imagined future decrease of oil reserves with its consequent increase in the price of raw materials for purely traditionally manufactured wood binders.

\section{Polystyrene as a Binder in Wood Composites Manufacture}

Polystyrene is a synthetic, aromatic, thermoplastic polymer made from the monomer styrene. Styrene was first produced on an industrial scale in 1931 by IG Farben industries in Geramny and a little later by the Dow Chemical Company in USA. Both companies employed the catalytic dehydrogenation of athylbenzene, which is still the main process used today [4]. Polystyrene is widely used for packaging applications and its Society for Plastic Industry code is 6, indicating the difficulty associated with its recycling. The common forms of polystyrene are general purpose polystyrene (GPPS), expanded polystyrene (EPS), high impact polystyrene (HIPS) and syndiotatic polystyrene (SPS). 


\section{Wood Composite Adhesives}
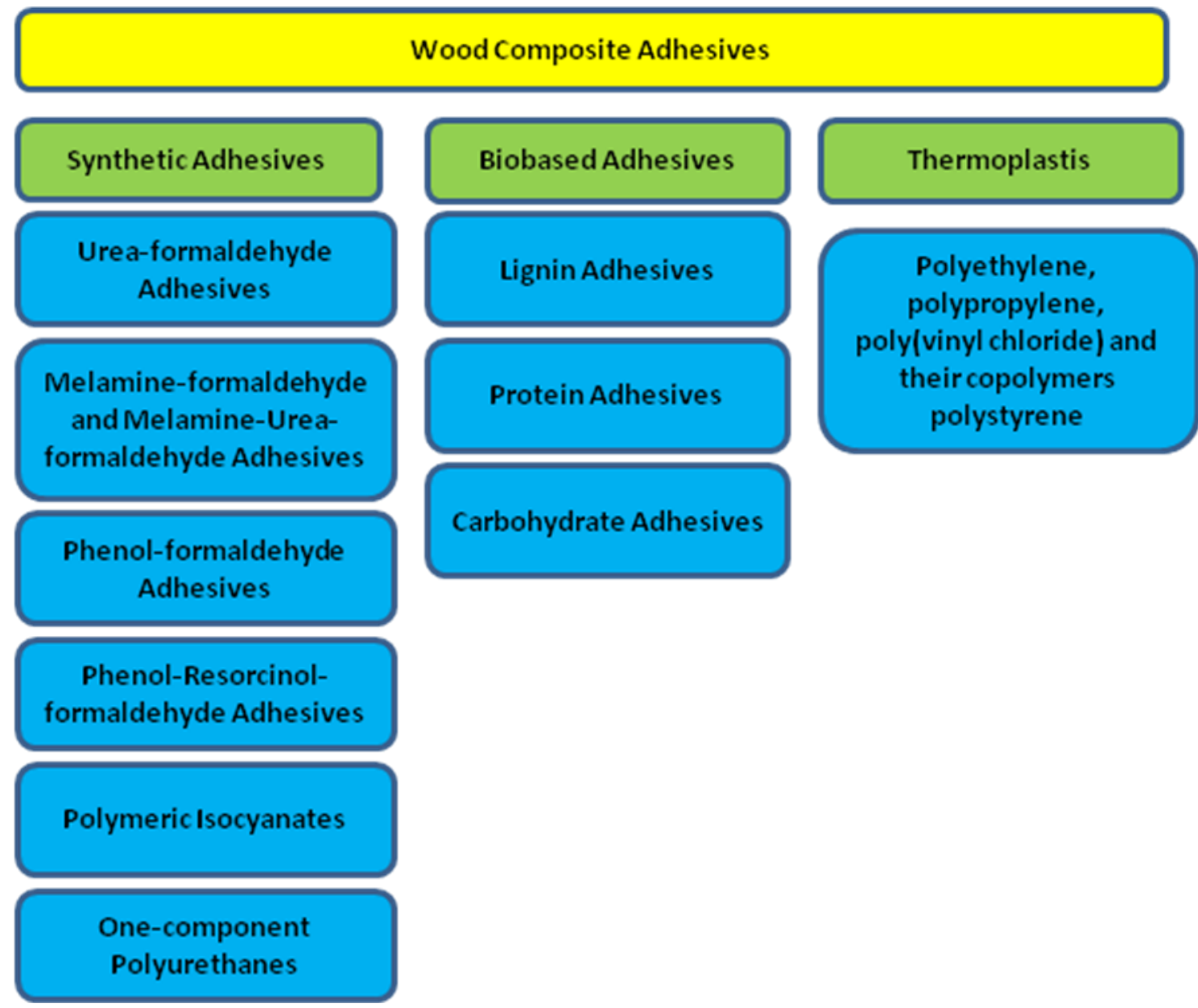
The 1st International Electronic Conference on "Green" Polymer Materials 2020, 5-25 November 2020

bonded plywoods. Poletto et al. [9] examined the effects of wood flour loading and coupling agent addition on the mechanical properties and morphology of wood thermoplastic composites from recycled expanded polystyrene and wood flour. The reported results indicated a reduction in mechanical strength as the wood flour content increased, but on using the coupling agent, the mechanical properties increased. Homkhiew et al. [10] developed high density wood-polyethylene comfrom rubberwood flour and sludge waste with improved mechanical strength on increase of sludge waste content. Akinyemi et al. [11] presented the results of experimental study on the production of particle boards from wastes of wood and expanded polystyrene foam. This study demonstrated that wood and expanded polystyrene foam wastes are sustainable materials for producing composite wood based panels that are still durable in moist environment. Hermawan et al. [12] evaluated the physical and mechanical properties of strand board bonded with disposal expanded polystyrene as binder. The results sevealed that the mechanical properties of the boards met the Japansese standards, however thickness swelling remained a problem. Chanhoun et al [13] examined the possibility of upgrading plastic waste, expanded polystyrene and wood, that pollute the environment of cities in Africa in general and those of Benin in particular. The study showed that, for the same polymer, the physical and mechanical characteristics are different depending on the granular composition (modulus of finesse) of the wood particles. In addition, the expanded polystyrene polymer provides high mechanical performance composites than those obtained with the plastic-based polymer. The thermal conductivity of composites made of wood wastes and expanded polystyrene was investigated by Agoua et al. [14]. The composite materials consist in that chips or sawdusts of wood sorted in particles of varied dimension and mixed according to a granular composition well defined. The different components are assembled with glue obtained from polystyrene of packing dissolves in a solvent. The thermal conductivity $\mathrm{k}$ determined for this type of composite shows that this one can be used in the realization of the partitions and suspended ceilings.

Polystyrene has been applied in the manufacture of lightweight gypsum-based composites. Merino et al. [5] studied the physical and mechanical behavior of lightweight gypsums using incorporating mixes of polystyrene wastes, both extruded (XPS) and expanded (EPS) polystyrene, in order to substitute perlite and vermiculite and achieve new materials complying with circular economy criteria. It was found that these gypsums containing polystyrenes comply with the current standards and have lower density than currently used lightweight gypsums and mechanical strengths. Expanded polystyrene has also been used for the manufacture of light weight concrete sandwich wall panels $[15,16]$.

\section{Conclusions}

The development of alternative value-added wood composites that use waste materials or recycled materials is becoming beneficial due to over exploitation of natural resources. In this context, an option to successfully utilize waste polystyrene and at the same time to avoid the environmental problems that formaldehyde adhesives cause, is its application as a binder in order to produce value-added wood composites. This review demonstrated that wood or wood waste and expanded polystyrene foam waste are low-cost and sustainable materials for producing wood composites with acceptable properties which can reduce waste disposal and provide cleaner production for the development of wood-based boards. In another connection, this approach of retraining wood or wastes of wood and polystyrene gotten from packing remove from service permits to produce economic and environment respectful composites. 
Funding: This research is co-financed by Greece and the European Union (European Social Fund -ESF) through the Operational Programme 'Human Resources, Development, Education and Lifelong Learning 2014-2020' in the context of the project 'Innovative wood plastic composites made from recycled polystyrene and recycled wood chips' (MIS 5048422)

Conflict of Interest: The authors declare no conflict of interest.

\section{References}

1. Papadopoulos, A.N. Advances in Wood Composites. Polymers 2020, 12, 48.

2. Papadopoulos, A.N. Advances in Wood Composites II. Polymers 2020, 12, 1552.

3. Pizzi, A.; Papadopoulos, A.N.; Policardi, F. Wood composites and their polymer binders. Polymers 2020, 12, 1115.

4. Chaukura, N., Gwenzi, W.; Bunhu, T.; Ruzixa, D.; Pumure, I. Potential uses and value added products derived from waste polystyrene in developing countries: A review. Resources, Conservation and Recycling 2016, 107, 157-165.

5. Merino, M.; Saez, P.; Longobardi, I.; Astorqui, J.; Porras-amores, C. Redesigning lightweight gypsum with mixes of polystyrene waste from construction and demolition waste. J of Cleaner Prod 2019, 220, 144-151.

6. Masri, T.; Ounis, H.; Sedira, L.; Kaci, A; Benchabane A. Characterization of new composite material based on date palm leaflets and expanded polystyrene wastes. Constr Build Mater 2018, 164, 410-418.

7. Pao, C.N.Z.; Yeng, C.M. Properties and characterization of wood plastic composites made from agrowaste materials and post-used expanded polyester foam. J Thermoplast Compos Mater 2019, 32, 951-966.

8. Song, W.; Wei, W.; Li, X.; Zhang, S. Utilization of polypropylene film as an adhesive to prepare formaldehyde-free, weather-resistant plywood-like composites: process optimization, performance evaluation, and interface modification. BioResources 2016, 12, 228-254.

9. Poletto, M.; Dettenborn, J.; Zeni, M.; Zattera, A.J. Characterization of composites based on expanded polystyrene wastes and wood flour. Waste Manag 2011, 31, 779-784.

10. Homkhiew, C.; Boonchouytan, W.; Cheewawuttipong, W.; Ratanawilai, T. Potential utilization of rubberwood flour and sludge waste from natural rubber manufacturing process as reinforcement in plastic composites. J Mater Cycles Waste Manag 2018, 20, 1792-1803.

11. Akinyemi, B.A.; Okonkwo, C.E.; Alhassan, E.A.; Ajiboye, M. Durability and strength properties of particleboards from polystyrene wood wastes. J of Mat. Cycles and Waste Manag 2019, 21, 1541-1549.

12. Hermawan, A.; Ohuchi, T., Fyjimoto, N. Manufacture of strand board bonded with disposal expanded polystyrene as binder. J. Fac. Agr., Kyushu Univ. 2010, 55, 107-110.

13. Chanhoun, M.; Padonou, S.; Adjovi, E.C.; Olodo, E.; Doko, V. Study of the implementation of waste wood, plastics and polystyrenes for various applications in the building industry. Constr Build Mater 2018, 167, 936-941.

14. Agoua, E.; Allognon-Houessou, E.; Adjovi, E.; Togbedji, B. Thermal conductivity of composites made of wastes of woodand expanded polystyrene. Constr Build Mater 2013, 41, 557-562.

15. Fernando, P.L.N.; Jayasinghe, M.T.R.; Jayasinghe, C. Structural feasibility of Expanded Polystyrene (EPS) lightweight concrete sandwich wall panels. Constr Build Mater 2017, 139, 45-51.

16. Carvalho, C.H.R.; Motta, L.A.C. Study about concrete with recycled expanded polystyrene. Revista Ibracon de Estruturas E Materials 2019, 12, 1390-1407. 